tion occurring during the later stages of the rising phase. The appearance of a noticeable " aqueous flare "-that is, the presence of protein in the aqueous humour-seemed to take place after the pressure had begun to rise steeply. Thus at B the flare was first definitely identified; at $C$ the current of cells in the aqueous humour ceased, indicating an increase in viscosity due to the presence of protein; at $\mathrm{D}$ the flare appeared to be maximal and clots of fibrin were observable.

In conclusion, we must emphasize that nitrogen mustard is a dangerous substance; there is reason to believe that the human eye is some five times more sensitive to its effects than the rabbit's eye, so that just a fraction of a milligram of nitrogen mustard in the conjunctival sac may be enough to cause symptoms as acute as those described here. There is no known antidote for the substance, so that the first measure to be taken is thorough and immediate irrigation of the eye with water or saline solution.

Hugh Davson, D.Se., Alfred Huber, M.D., Institute of Ophthalmology, REFERENCE Judd Street, London

Davson, H., and Quilliam, J. P. (1947). Brit. J. Ophthal., 31, 717.

\section{Congenital Atresia of the Oesophagus}

In 1944 Haight, in America, reported the first case of congenital atresia of the oesophagus successfully treated by anastomosis. Franklin (1947) described the first two successful cases treated in this country, and since then there have been several, as yet unpublished, successes. In reporting another successful case it is my purpose to describe certain variations in operative technique and postoperative management which are considered of value.

\section{CASE RePort}

A full-term female child weighing $8 \frac{1}{2} \mathrm{lb}$. $(3.85 \mathrm{~kg}$.) was admitted to the Alder Hey Children's Hospital on May 5, 1949 , when 5 days old, with a history of regurgitation of all feeds since birth, associated with coughing, choking, and cyanosis. In spite of the length of history the child's general condition was satisfactory on admission apart from moderate dehydration. A small rubber catheter was passed into the oesophagus and $1 \mathrm{ml}$. of iodized oil was injected through this tube. Radiographs showed a dilated blind pouch ending at the level of the third thoracic vertebra. There was air in the stomach.

The child was nursed in an oxygen tent and the pharynx aspirated at frequent intervals. Penicillin, 250,000 units, was given intramuscularly and an intravenous glucose-saline infusion was started.

Operation.-Endotracheal oxygen and ether was supplemented by curare (Dr. G. J. Rees). The child was placed on her left side with a small sandbag underneath the lower ribs and her right arm raised above her head. An incision was made atong the fourth intercostal space from the lateral border of the sacrospinalis to the anterior axillary line. The intercostal muscles were divided down to the parietal pleura and the pleura was gradually dissected off the chest wall. The ribs were slowly spread with the aid of a mastoid retractor, while the pleura was separated in an upwards and backwards direction. At the apex of the lungs some difficulty was experienced in dissecting the pleura of the chest wall and a large hole was torn into the pleural cavity. This gave rise to some temporary respiratory distress, which was, however, quickly overcome by occluding the hole with a moist piece of lint and by controlled respiration. The blind oesophageal pouch was easily identified by manipulating a catheter in it. After dividing the vena azygos the lower oesophageal segment was discovered. It was found to be attached to the back of the trachea just above its bifurcation. and the distal segment was divided. The upper and lower segThe fistula was clamped and tied with strong chromic catgut ments could be brought together without tension. The blind oesophageal pouch was opened. The two segments were now anastomosed by means of a single layer of about a dozen interrupted silk sutures, on atraumatic needles, around a thin rubber catheter which had been passed down into the stomach and up into the mouth. The wound was dusted with penicillin powder and closed in layers around a small drainage-tube lying in the extrapleural space. The operation was completed in 85 minutes.

Post-operative Management.-The child was returned to an oxygen test, intravenous fluids were continued, and penicillin was given orally and by intramuscular injection. Her position was often changed and the pharynx was aspirated at half-hourly intervals. The tube draining the extrapleural space was connected to a Woulfe's bottle.

On May 6 her condition was excellent. Small feeds of $\frac{1}{2} \mathrm{oz}$. $(14 \mathrm{ml}$.) glucose-saline were given through the stomach catheter. In the afternoon the infant vomited up the catheter and it was not reinserted. Next day the drip stopped early in the morning and was taken down. Oral feeding was instituted. At first a feed of $\frac{1}{2} \mathrm{oz}$. of saline coloured with gentian violet was given. There was no discharge from the drainage-tube. Then $\frac{1}{2} \mathrm{oz}$. of breast milk was given at two-hourly intervals and the volume of the feeds was gradually inereased.

On May 8 the child was taking $2 \frac{1}{2} \mathrm{oz}$. $(71 \mathrm{ml}$.) of breast milk at three-hourly intervals without difficulty. No vomiting occurred and there was no discharge from the drainage-tube. On May 10 penicillin was discontinued and the drainage-tube removed. On May 13 the sutures were removed and the wound had healed.

The child made an uninterrupted recovery and was discharged on the 40th post-operative day. At the time of writing she is 11 weeks old and weighs $12 \mathrm{lb}$. (5.4 kg.).

\section{COMMENT}

The operative approach differs from that of Haight (1944), Ladd and Swenson (1947), Franklin (1947), Swenson (1947) and others, and is the one used by Mr. Denis Browne. It provides an excellent exposure of the upper mediastinum and avoids time-consuming rib-resection. It involves, however, a more extensive separation of the parietal pleura from the chest wall and there is some danger of post-operative pulmonary collapse of the upper lobe. A rent of the parietal pleura may occur and give rise to temporary respiratory embarrassment, but this can be checked by controlled respiration anaesthesia and it seems unnecessary and time-consuming to repair it.

It had been our intention to give feeds by stomach-tube for at least five days, but the tube was regurgitated on the day after operation and it was thought inadvisable to reinsert it. Feeding by mouth was started 36 hours after operation, at first using coloured saline to detect any leak from the anastomosis, and then breast milk. We consider that the early commencement of oral feeding was one of the main reasons for the child's speedy recovery. Detection of a leaky anastomosis by instillation of iodized oil into the child's oesophagus and observing it under $x$ ray was not undertaken because it was thought that this method would not reveal a small leak and that a coloured aqueous solution would prove more satisfactory and less irritant.

I wish to thank Miss Isabella Forshall for her most helpful advice during both the operation and the post-operative treatment, and Dr. R. McL. Todd and Dr. A. C. Kirby, whose skilled co-operation during the post-operative period has been invaluable. The rapidity and smoothness of the child's recovery were largely due to Dr. W. J. Gourley's and Sister Owen's constant and faithful attention.

\section{P. P. RickhaM, M.S., F.R.C.S.,}

Senior Surgical Registrar, Alder Hey and Royal Liverpool Children's Hospitals, Liverpool.

\section{REFERENCES}

Franklin, R. H. (1947). Lancet, 2, 243.

Haight, C. (1944). Ann. Surg., 120, 623.

and Townsley, H. A. (1943). Surg. Gynec. Obstet., 76, 672.

Ladd, W. E., and Swenson, O. (1947). Ann. Surg., 125, 23.

Swenson, O. (1947). Surgery, 22, 324. 